\title{
Granuloma Periférico de Células Gigantes: Revisão da Literatura
}

\section{Peripheral Giant Cell Granuloma: Literature Revision}

\author{
Pedro Henrique Cossu Vallejo ${ }^{1}$, Hélio Massaiochi Tanimoto ${ }^{1,2}$ \\ ${ }^{1}$ Centro Universitário da Fundação Educacional de Barretos - UNIFEB \\ ${ }^{2}$ Hospital de Câncer de Barretos - Fundação Pio XII
}

\begin{abstract}
Resumo
O granuloma periférico de células gigantes (GPCG) se manifesta exclusivamente na cavidade bucal e tem sua origem no ligamento periodontal ou no periósteo do osso alveolar. O GPCG apresenta um crescimento semelhante a tumor relativamente comum na cavidade oral, porém não representa uma neoplasia verdadeira, mas sim uma lesão benigna reacional causada por irritação local ou trauma. O objetivo do trabalho em questão é realizar uma revisão da literatura sobre GPCG. Essa lesão aparece mais em mulheres, com incidência maior entre a $4^{\mathrm{a}}$ e $6^{\mathrm{a}}$ décadas de vida, sendo mais frequente na região posterior da mandíbula. Geralmente se apresenta como nódulo pediculado ou séssil em gengiva ou rebordo alveolar, de coloração vermelha ou púrpura, podendo ter superfície ulcerada. Possui acentuado potencial de crescimento, o que gera reabsorção do osso subjacente à lesão. $O$ tratamento mais indicado é a excisão cirúrgica e curetagem do osso, a fim de evitar recidivas. O granuloma piogênico e o fibroma ossificante periférico são lesões que se assemelham, consequentemente são classificadas como diagnóstico diferencial, e como não possuem características patognomônicas, utiliza-se o exame histopatológico para elucidar o diagnóstico definitivo. Portanto, realizar uma correta anamnese e conhecer as características clínicas, radiográficas e histopatológicas são fatores indispensáveis para determinar o diagnóstico correto e obter sucesso no tratamento. Além disso, deve-se realizar a proservação do caso.
\end{abstract}

Palavras chave: doença periodontal; lesão de células gigantes periférica; diagnóstico diferencial.

\begin{abstract}
Peripheral giant cell granuloma (GPCG) occurs exclusively in the oral cavity and originates from the periodontal ligament or the periosteum of the alveolar bone. Although the GPCG shows a tumor-like growth relatively common in the oral cavity, it is not a true neoplasm, but a benign reaction to injury caused by local irritation or trauma. This work aims to carry out a literature review on GPCG. This lesion appears more in females, with a higher incidence between the 4th and 6th decades of life, being more frequent in the posterior region of jaw. It usually presents as a pedunculated or sessile nodule in the gingiva or alveolar ridge. The color can be red or purple, and it may present an ulcerated surface. It has a strong growth potential, which generates resorption of the underlying bone to the lesion. The most indicated treatment is the surgical excision and curettage of the bone in order to avoid relapses. GPCG resembles the pyogenic granuloma and peripheral ossifying fibroma, consequently classified as differential diagnosis. Since they do not have pathognomonic characteristics, the definitive diagnosis is elucidated with histopathological examination. Therefore, a correct anamnesis and clinical knowledge, along with radiographic and histopathological characteristics are indispensable factors to determine the correct diagnosis and successful treatment. In addition, the case must be analyzed frequently.
\end{abstract}

Key-words: periodontal disease; peripheral giant cell lesion; differential diagnosis.

Centro Universitário da Fundação Educacional de Barretos - UNIFEB. Avenida Professor Roberto Frade Monte, 389 - Aeroporto - CEP: 14283-078 - Barretos (SP), Brasil E-mail: drpedrohcv@gmail.com e telefone: (17) 997745930

Recebido em: 28/12/2017

Aceito em: 05/04/2018 


\section{Introdução}

O tecido periodontal é foco frequente de processo inflamatório crônico que ocorre como resposta à interação dos produtos bacterianos com as reações do sistema imune. No aspecto histopatológico, a maioria das lesões apresenta infiltrado inflamatório, caracterizado por linfócitos, plasmócitos e macrófagos, fibroblastos e proliferação capilar, que representam a reação de granulação (SILVEIRA, 1989).

Em alguns casos de periodontopatias, podem se desenvolver respostas teciduais específicas, com proliferação excessiva de fibras, de vasos ou de células gigantes. A produção excessiva de fibras, chamada de fibroplasia, pode estar relacionada a crescimentos gengivais associados ao uso de medicamentos ou a crescimentos de origem genética. Já a proliferação de vasos sanguíneos, chamada de angiogênese, em excesso pode caracterizar uma lesão frequente do periodonto, que é o granuloma piogênico (HOLMSTRUP; REIBEL, 1997).

A presença de células gigantes no periodonto é uma característica das lesões de células gigantes, envolvendo o granuloma periférico de células gigantes (GPCG), podendo ser chamado também de lesão periférica de células gigantes (LPCG), granuloma de células gigantes central (GCGC), cisto ósseo aneurismático, querubismo e tumor marrom do hiperparatireoidismo. Dessa forma, como os achados histopatológicos são comuns entre essas lesões, o diagnóstico definitivo deve estar associado aos aspectos clínicos/radiográficos; localização periosteal no GPCG, ou endosteal no GCGC; história de trauma sugerindo cisto ósseo aneurismático e exames bioquímicos na pesquisa de alterações endócrinas confirmando ou não hiperparatireoidismo (FALABELLA; FISCHER, 2008; NEVILLE et al., 2009; FRANÇA et al., 2010).

A LPCG se manifesta exclusivamente na cavidade bucal e tem sua origem no ligamento periodontal ou no periósteo do osso alveolar. O GPCG apresenta um crescimento semelhante a tumor relativamente comum na cavidade oral, porém não representa uma neoplasia verdadeira, mas sim uma lesão reacional causada por irritação local ou trauma. Antigamente era chamado de granuloma reparativo de células gigantes, contudo, essa nomenclatura caiu em desuso, pois não há atividade reparadora (CAPELOZZA et al., 2007; NEVILLE et al., 2009).
Katsikeris, Kakarantza-Angelopoulo e Angelopoulo (1988) estudaram 1.180 casos de GPCG relatados na literatura e mostraram uma predileção pelo sexo feminino, com incidência maior entre 40 e 60 anos, sendo mais frequente na mandíbula.

As características clínicas mostram lesões pediculadas ou sésseis que ocorrem na gengiva ou processo alveolar, de coloração vermelha ou púrpura, geralmente ulceradas; possuem acentuado potencial de crescimento, levando às vezes à erosão do osso subjacente (HOLMSTRUP; REIBEL, 1997).

O tratamento mais indicado é a excisão cirúrgica e curetagem do osso, caso este esteja comprometido, para promover a retirada do periósteo e evitar assim a recidiva da lesão. Em seguida, realiza-se a proservação do paciente (GANDARA et al., 2002).

O objetivo do trabalho em questão é realizar uma revisão da literatura do GPCG, apresentando sintomatologia, características clínico-radiográficas e histopatológicas, semiotécnicas para o diagnóstico, diagnóstico diferencial, forma de tratamento, prognóstico e proservação.

\section{Material e Método}

Realizou-se pesquisa bibliográfica na qual foram utilizados livros que abordam a literatura na área de estomatologia e bases eletrônicas de dados, como Google Acadêmico, Scielo e Bireme. A estratégia de busca foi realizada usando palavras-chaves do assunto, tais como: lesão de células gigantes periférica, diagnóstico diferencial e tratamento do granuloma periférico de células gigantes.

\section{Revisão da Literatura}

A fim de proporcionar uma melhor leitura e compreensão do artigo em questão, esta seção foi subdividida em itens, explicando como se desenvolve o GPCG, suas características clínicas, radiográficas e histológicas, como diagnosticar, quais as outras lesões que compõem o diagnóstico diferencial e como é seu tratamento e prognóstico.

\section{Definição e Etiologia}

O granuloma de células gigante, ou epúlide de células gigantes, é uma lesão benigna que apresenta proliferação não neoplásica do tecido conjuntivo, constituída de células gigantes multinucleadas que se agregam. Ainda possui etiologia desconhecida, 
porém é evidente a associação de traumas e agentes irritantes locais. Por ser uma lesão reacional, estão entre os fatores predisponentes ao seu aparecimento: raízes residuais, próteses, restaurações mal-adaptadas, extrações dentárias, placa e cálculos dentais, implantes e periodontite. Geralmente as lesões ocorrem em rebordo alveolar e fórnix vestibular (CAPELOZZA et al., 2007; NEVILLE et al., 2009; FRANÇA et al., 2010).

De acordo com Günham et al. (1998) e França et al. (2010), pode ocorrer em todas as idades, porém são mais frequentes entre a terceira e a sexta década de vida, acometendo mais o sexo feminino (53\%) do que o sexo masculino (47\%). A principal localização onde a LPCG se desenvolve é na mandíbula (53\%), geralmente em região posterior $(73 \%)$.

As lesões em pacientes adultos são geralmente menos agressivas e pequenas, com diâmetro de até 2 centímetros. Porém, a ocorrência da LPCG em crianças de até 10 anos pode chegar a $9 \%$ e varia de $6,5 \%$ a $12,7 \%$ em pacientes de 11 a 20 anos. Além disso, o GPCG é mais agressivo em crianças, podendo atingir proporções maiores, chegando até 4 centímetros de diâmetro e, em alguns casos, dobrando de tamanho (KATSIKERIS et al., 1988; DAYAN et al., 1990; BODNER et al., 1997; FLAITZ, 2000).

O rápido crescimento da lesão pode causar o deslocamento dos dentes envolvidos na região. As lesões ocorrem geralmente em pacientes que apresentam condições de higiene bucal insatisfatória (CAPELOZZA et al., 2007).

As taxas de recorrências podem variar de 4,9\%, segundo Giansanti e Waldron (1969), até 70,6\%, como afirma Andersen et al. (1973). Esse número elevado de recidivas é geralmente atribuído às técnicas cirúrgicas que não empregam a remoção do ligamento periodontal, raspagem da superfície do dente e do periósteo envolvido, confirma Marx e Stern (2003).

\section{Características Clínicas}

O GPCG ocorre exclusivamente em gengiva inserida ou no rebordo alveolar, caracteriza-se por crescimento nodular gengival exofítico, de coloração vermelha-escura ou vermelha-azulada (figura 1 e 2), geralmente assintomática e com tendência a sangramento, apresentando base séssil ou pediculada, diferentes dimensões, variando de 0,5 até 1,5 centímetro de diâmetro. Porém, grandes lesões são vistas ocasionalmente, podendo causar deslocamento dos dentes adjacentes e reabsorção do osso subjacente. A superfície da lesão é lisa e brilhante, podendo ser ulcerada ou não. A evolução dessa lesão é rápida, atingindo 1 centímetro em poucas semanas, acometendo grande parte da população (TORRES, 1986; FALLABELA; FISCHER, 2008; NEVILLE et al., 2009; FRANÇA et al., 2010; KIGNEL et al., 2013).

\section{Características Radiográficas}

Apesar de o GPCG ser uma lesão que se desenvolve dentro dos tecidos moles, algumas vezes pode causar reabsorção do osso subjacente em forma de "taça" (figura 3). Isso acontece por causa da compressão exercida pela lesão. A radiografia mostra uma zona radiolúcida circundada por um halo radiopaco, podendo conter pontos radiopacos no interior da lesão, indicando pontos de calcificação. Costuma apresentar limites relativamente regulares frequentemente com discretas trabéculas, ocasionalmente associadas com espículas ósseas ou irregularidades sugestivas de trauma evidente (CASTRO, 1992; NEVILLE et al., 2009).

De acordo com o trabalho de Anneroth e Sigurdson (1983), de 23 lesões de GPCG, 15 apresentaram alterações no osso alveolar. Segundo Flaitz (2000), na radiografia periapical do GPCG demonstra reabsorção superficial em forma de taça (côncava) do osso alveolar e alargamento do espaço do ligamento periodontal.

Gandara et al. (2002) estudaram 13 casos de GPCG, dos quais 5 mostraram reabsorção do osso alveolar, alargamento do espaço periodontal e reabsorção superficial da cortical do rebordo.

\section{Características Histopatológicas}

No exame histopatológico de uma lâmina da lesão de GPCG, nota-se um estroma de tecido conjuntivo com uma proliferação de células gigantes multinucleadas permeadas por células mesenquimais volumosas ovoides e fusiformes. Algumas dessas células podem conter poucos núcleos ou várias dúzias, e o tamanho dos núcleos também pode variar desde grandes e vesiculosos até pequenos e picnóticos (figura 4 e 5). É de fácil verificação e muito comum o processo mitótico nas células mesenquimais de fundo (NEVILLE et al., 2009; FRANÇA et al., 2010).

Outra característica histopatológica dessa lesão é a hemorragia intersticial abundante em 
todo aumento de volume, que geralmente resulta no depósito de pigmento de hemossiderina, especialmente na periferia da lesão. A superfície da mucosa de revestimento encontra-se ulcerada em 50\% dos casos. Geralmente uma zona de tecido conjuntivo denso separa a proliferação de células gigantes da superfície da mucosa. Frequentemente, estão presentes células inflamatórias agudas e crônicas. Áreas de formação de osso reacional ou de calcificações distróficas não são incomuns (NEVILLE et al., 2009; FRANÇA et al., 2010).

Nas superfícies das lesões que se apresentam ulceradas é possível notar microscopicamente um exsudato serofibrinoso com grande número de polimorfonucleares sobre um tecido de granulação. Em alguns casos, a lesão pode apresentar-se recoberta por epitélio do tipo estratificado pavimentoso hiperplásico, paraqueratinizado com intensa exocitose e fragmentos de tecido mineralizado (CAPELOZZA et al., 2007).

Em seu trabalho, Torres (1986) analisou 46 lesões de GPCG quanto à histopatologia e mostrou que o epitélio das lesões se apresentava paraceratinizado em $69 \%$ das lesões. Em $90 \%$ dos casos de GPCG, encontrou infiltrado inflamatório crônico com predominância de linfócitos, área com material calcificado, mais frequentemente osteoide.

Carvalho et al. (1995) avaliaram 6 casos de GPCG utilizando microscopia eletrônica de transmissão e perceberam a presença de células mononucleares com sinais característicos de fagocitose. Os mesmos autores analisaram 40 casos através de imuno-histoquímica e observaram reação positiva em $2 / 3$ das lesões para a proteína S-100, o que sugere a presença de células de Langerhans e reação positiva para o CD-68, mostrando uma grande presença de células mononucleares no estroma dessas lesões.

As células gigantes multinucleadas se originam dos osteoclastos, podendo se formar no local ou trazidas pela circulação sanguínea. Isso pode ser evidenciado pela análise microscópica das lesões de GPCG, que mostram forte reatividade ao MB1, que é um anticorpo reativo com osteoclastos, e fosfatase ácida, enzima muito produzida pelos osteoclastos (BONETTI et al., 1990; TIFFEE; AUFDEMORTE, 1997; CAPELOZZA et al., 2007).

Para investigar uma possível atividade tumoral, Mighell et al. (1996) realizaram um estudo e observaram ausência de imunorreatividade das células gigantes para o PCNA e Ki-67. Pammer et al. (1998) detectaram núcleos apoptóticos nas células gigantes, demonstrando a natureza reativa dessas lesões. E no estudo de Souza et al. (2000), também mostrou imunorreatividade nula das células gigantes para o gene p53.

\section{Diagnóstico Diferencial}

A aparência clínica é semelhante ao granuloma piogênico (figura 6), tumor metastático e ao fibroma ossificante periférico (figura 8), embora o GPCG seja ocasionalmente mais azul-arroxeado, comparado ao vermelho-brilhante de um granuloma piogênico típico (FALABELLA; FISCHER, 2008; NEVILLE et al., 2009).

Embora o granuloma periférico de células gigantes desenvolva-se dentro dos tecidos moles, algumas vezes pode ser observada radiograficamente uma reabsorção em forma de "taça" do osso alveolar subjacente. Nesses casos, pode ser difícil determinar se o aumento de volume se origina de uma lesão periférica ou de um granuloma de células gigantes central que rompeu a cortical óssea, invadindo os tecidos moles gengivais (NEVILLE et al., 2009).

Analisando histologicamente o GPCG, GCGC (figura 7), cisto ósseo aneurismático, querubismo e o tumor marrom do hiperparatireoidismo, todas apresentam células gigantes. Portanto, a análise minuciosa e detalhada das características clínicas-radiográficas e a realização de exames complementares específicos para cada lesão são de extrema importância para definir o diagnóstico correto (FALABELLA; FISCHER, 2008; NEVILLE et al., 2009; FRANÇA et al., 2010).

\section{Semiotécnica para Diagnóstico}

Para que a coleta de sinais e sintomas do paciente seja realizada de forma correta, deve-se realizar uma boa anamnese seguida de um exame intra e extraoral. Além disso, a inspeção visual-tátil da lesão é de primordial importância, pois se for bem realizada, permite que o profissional obtenha um direcionamento para o diagnóstico diferencial e de quais exames complementares necessitará (KIGNEL, 2013).

No caso da LCGP, o exame radiográfico é o primeiro exame complementar a ser solicitado, já que dessa forma é possível analisar se existe ou não reabsorção óssea. Outro exame a ser solicitado é a biópsia da lesão, podendo ser ela excisional ou incisional, e logo após enviar o material coletado no processo cirúrgico para análise 
histopatológica. Dessa forma, torna-se possível verificar as microestruturas anatomopatológicas e os tipos de células que a lesão apresenta, auxiliando demasiadamente na determinação do diagnóstico definitivo (KIGNEL, 2013).

Como as características histopatológicas são muito parecidas nas lesões de GPCG, GCGC, cisto ósseo aneurismático, querubismo e o tumor marrom do hiperparatireoidismo, deve-se analisar outras características de cada lesão que sejam diferentes entre elas. No caso do GPCG, tem localização periosteal; já o GCGC tem localização endosteal, o cisto ósseo aneurismático necessita a realização do exame de punção aspirativa, o querubismo possui traço autossômico dominante e o tumor marrom do hiperparatireoidismo exige exames bioquímicos para pesquisar alterações

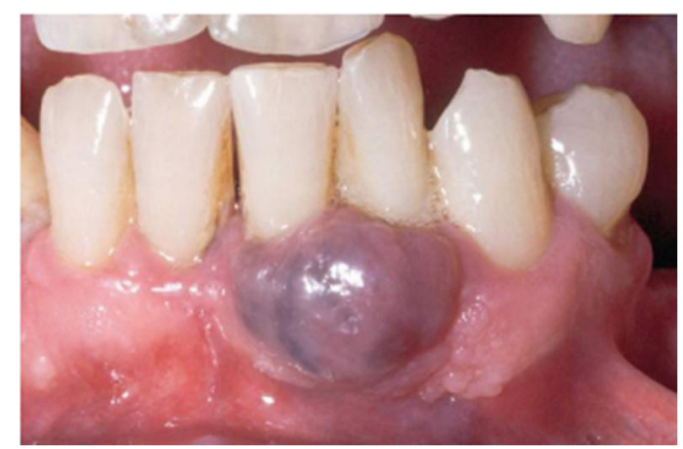

Figura 1: Caso clínico de GPCG com cor azul-arroxeada na gengiva inserida da mandíbula. Fonte: NEVILE et al, 2009. endócrinas (FALABELLA; FISCHER, 2008; NEVILLE et al., 2009; FRANÇA et al., 2010).

\section{Tratamento e Prognóstico}

$\mathrm{O}$ tratamento mais adequado para o GPCG consiste na excisão cirúrgica da lesão, remoção do fator irritante e consequentemente proservação da área. É de suma importância que seja realizada a curetagem do osso, a fim de remover o periósteo, amenizando a chance de uma recidiva da lesão. A raspagem dos dentes adjacentes também deve ser cuidadosamente realizada, para retirar qualquer fonte de irritação e minimizar ainda mais o risco de recidiva, já que esta é relatada em $10 \%$ dos casos. Caso a lesão reapareça, a excisão deve ser feita novamente. Por ser uma lesão benigna, o prognóstico é favorável (CAPELOZZA et al., 2007;

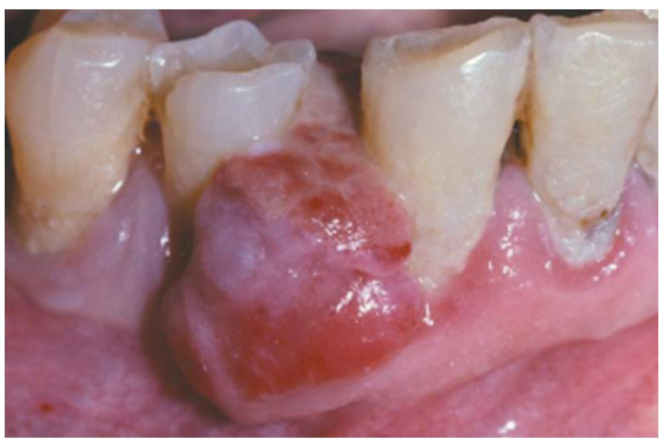

Figura 2: Caso clínico de GPCG com presença de úlcera. NEVILE et al, 2009.

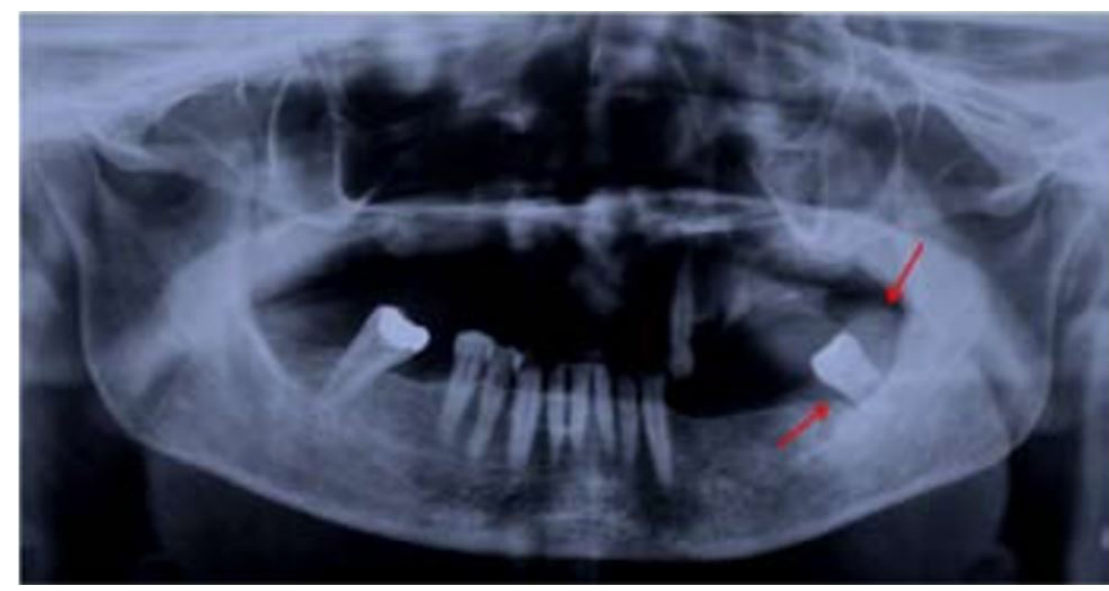

Figura 3: Radiografia panorâmica demonstrando a reabsorção óssea na região do dente 38, causada por GPCG. FRANÇA et al, 2010. 


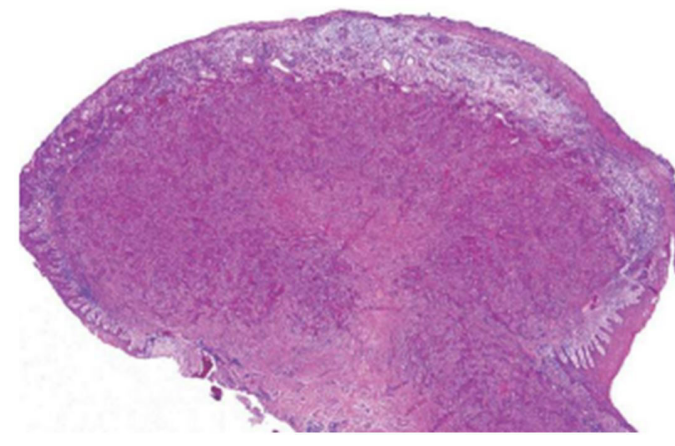

Figura 4: Corte histológico de GPCG na gengiva em pequeno aumento. NEVILE et al, 2009.

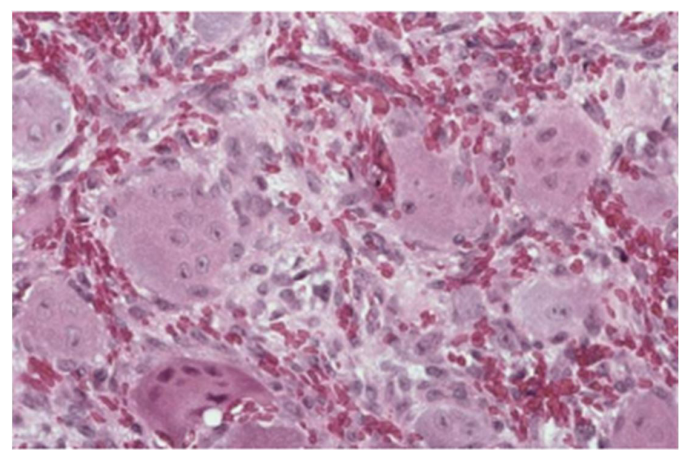

Figura 5: Corte histológico de GPCG em maior aumento. NEVILE et al, 2009.

FALABELLA; FISCHER, 2008; NEVILLE et al., 2009; FRANÇA et al., 2010).

\section{Discussão}

ALPCG se apresenta como uma lesão reacional, que não possui etiologia conhecida, porém é associada a agentes traumáticos crônicos, como próteses e restaurações mal-adaptadas, cálculo subgengival, entre outros.

Fortes et al. (2002), analisando casos de GPCG, confirmaram que esta é uma lesão praticamente exclusiva do rebordo alveolar e gengiva, de cor predominantemente vermelho-rosado ou azul-arroxeado, quando comparado com o granuloma piogênico, de base pediculada.

Por não apresentar características patognomônicas, a lesão deve ser examinada microscopicamente para elucidar o diagnóstico definitivo e anular as

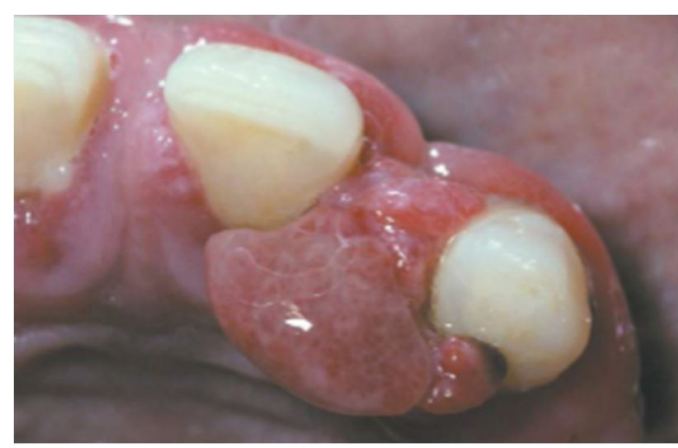

Figura 6: Granuloma piogênico. Fonte: NEVILE et al, 2009.

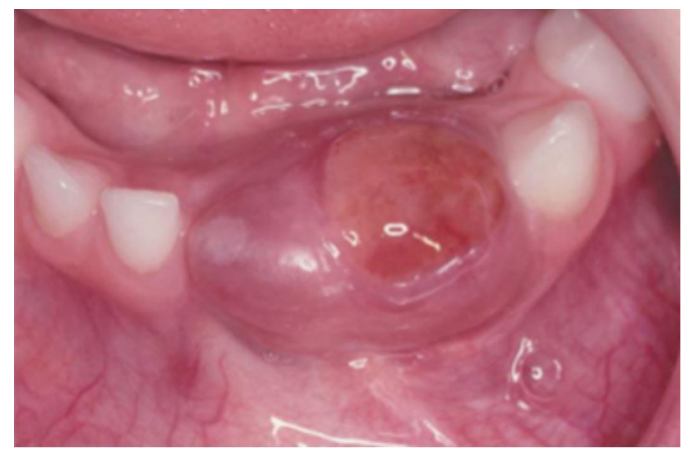

Figura 7: Granuloma de células gigantes central. Fonte: NEVILE et al, 2009.

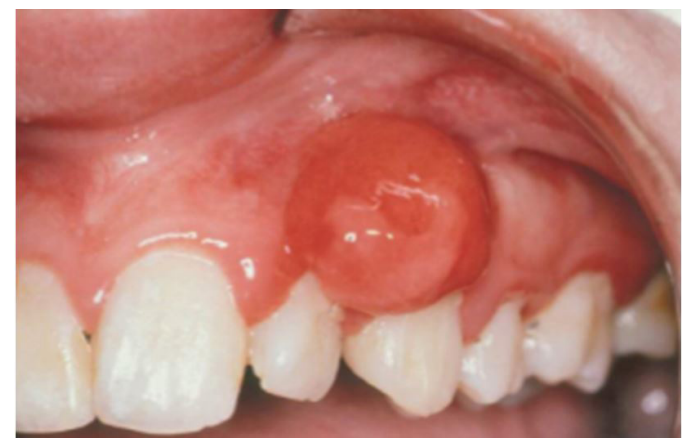

Figura 8: Fibroma ossificante periférico. Fonte: NEVILE et al, 2009.

hipóteses de outras lesões malignas. Para eliminar a hipótese de tumor marrom do hiperparatireoidismo, deve-se realizar exame de fosfatase alcalina, índice de cálcio, fosfato e paratormônio no sangue.

\section{Conclusão}

As características clínicas, radiográficas e histopatológicas são de fundamental importância no conhecimento dos cirurgiões-dentistas, já que 
o correto diagnóstico é fator imprescindível para obter o sucesso no tratamento. Além disso, estes profissionais devem possuir o domínio das técnicas cirúrgicas e realizar uma adequada proservação do caso, pois existe possibilidade de recidiva.

\section{Referências Bibliográficas}

ANDERSEN, L.; FEJERSKOV, O.; PHILIPSEN, H. P. Oral giant cell granulomas. Acta Pathologica et Microbiologica Scandinavica, v. 81, p. 606616, 1973.

ANNEROTH, G.; SEGURDSON, A. Hyperplastic lesions of gingival and alveolar mucosa. A study of 175 cases. Acta Odontologica Scandinavica, v. 41, p. 75-86, 1983.

BODNER, L.; PEIST, M.; GATOT, A. Growth potential of peripheral giant cell granuloma. Oral Surgery, Oral Medicine, Oral Pathology, Oral Radiology, and Endodontics, v. 83, p. 548-551, 1997.

BONETTI, F.; PELOSI, G.; MARTIGNONI, G. Peripheral giant cell granuloma: evidence for osteoclastic differatiation. Oral Surgery, Oral Medicine, and Oral Pathology, v. 70, p. 471475, 1990.

CAPELOZZA, A. L. A.; TAVEIRA, L. A. A.; PAGIN, O. Lesão periférica de células gigantes - Relato de caso. Saluvista, v. 26, n. 1, p. 99-104, 2007. Disponível em $<$ https://www.researchgate.net/ publication/266340630_LESAO_PERIFERICA_DE CELULAS_GIGANTES_RELATO_DE_CASO $>$. Acesso em 08 dez. $201 \overline{7}$.

CARVALHO, Y. R.; LOYOLA, A. GOMES, R. S.; ARAUJO, V. C. Peripheral giant cell granuloma. An immunohistochemical and ultrastructural study. Oral Diseases, v. 1, p. 20-25, 1995.

CASTRO, A. L. Estomatologia. 1. ed. Araçatuba: Santos, 1992. 84 p.

DAYAN, D.; BUCHNER, A.; SPIRER, S. Bone formation in peripheral giant cell granuloma. Journal of Periodontology, v. 61, p. 444-446, 1990.

FALABELLA, M. E. V.; FISCHER, R. G. Granuloma periférico de células gigantes - caso clínico. Revista Periodontia, v. 18, n. 1, p. 38-43, 2008. Disponível em $<$ http://www.revistasobrape. com.br/arquivos/marco2008/artigo6.pdf > . Acesso em 20 de out. 2017.

FLAITZ, C. M. Peripheral giant cell granuloma: a potentially aggressive lesion in children. Pediatric Dentistry, v. 22, n. 3, p. 232-233, 2000.

FRANÇA, D. C. C. et al. Granuloma Periférico de Células Gigantes: Relato de Caso. Revista de Cirurgia e Traumatologia Buco-Maxilo-Facial, v. 10, n. 3, p. 29-32, 2010. Disponível em $<$ http:// revistacirurgiabmf.com/2010/v10n3/5.pdf $>$. Acesso em 20 de out. 2017.

FORTES, T. M. V. et al. Estudo epidemiológico de lesões proliferativas não neoplásicas da mucosa oral - análise de 20 anos. Ciência Odontológica Brasileira, v. 5, n. 3, p. 54-61, 2002.

GANDARA, J. M. et al. Granuloma Periférico de células gigantes. Revisión de 13 casos clínicos. Medicina Oral, v. 7, p. 254-259, 2002.

GIANSANTI, J. S.; WALDRON, C. A. Peripheral giant cell granuloma. Journal of Oral Surgery, v. 27, p. 788-791, 1969.

GUNHAM, M. et al. Estrogen and progesterone receptors in the peripheral giant cell granulomas of the oral cavity. Journal of Oral Science, v. 40, p. 57-60, 1998.

HOLMSTRUP, P.; REIBEL, J. Tumores e cistos do periodonto. In: LINDHE, J. Tratado de Periodontia Clínica e Implantologia Oral. 3. ed. Rio de Janeiro: Guanabara Koogan, 1997. p. 253-254.

KATSIKERIS, N.; KAKARANTZAANGELOPOULO, E.; ANGELOPOULO, A. P. Peripheral giant cell granuloma. Clinicopathologic study of 224 new cases and review of 956 reported cases. Journal of Oral and Maxillofacial Surgery, v. 17, p. 94-99, 1988.

KIGNEL, S. Estomatologia-Bases do Diagnóstico para o Clínico Geral. 2. ed. São Paulo: Santos, 2013. p. 190-191.

MARX, R. E.; STERN, D. Oral and Maxillofacial Pathology: a rationale for diagnosis and treatment. Surrey: Quintessence Books, 2003. 908 p. 
MIGHELL, A. J.; ROBINSON, P. A.; HUME, P. J. PCNA and Ki-67 imunoreactivity in multinucleated cells of giant cell fibroma and peripheral giant cell granuloma. Journal of Oral Pathology \& Medicine, v. 25, p. 193-199, 1996.

NEVILLE, B. W. et al. Patologia Oral e Maxilofacial. 3. ed. Rio de Janeiro: Elsevier, 2009. p. 522-523.

PAMMER, J. et al. Expression of regulatory apoptotic proteins in peripheral giant cells granulomas and lesions containing osteoclast-like giant cells. Journal of Oral Pathology \& Medicine, v. 27, p. 267-271, 1998.

SILVEIRA, J. C. S. Patogenia e Histopatologia da Bolsa Periodontal. In: LASCALLA, N. T.;
MOUSSAlli, N. H. Periodontia Clínica. 2. ed. São Paulo: Artes Médicas, 1989. p. 186-198.

SOUZA, P. E.; MESQUITA, R. A.; GOMEZ, R. S. Evaluation of p53, PCNA, Ki- 67, MDM2 and AgNOR in oral peripheral and central giant cell lesions. Oral Diseases, v. 6, p. 35-39, 2000.

TIFFEE, J. C.; AUFDEMORTE, T. B. Markers for macrophage and osteoclast lineages in giant cell lesions of the oral cavity. Journal of Oral and Maxillofacial Surgery, v. 10, p. 1108-1112, 1997.

TORRES, S. R. Granuloma de Células Gigantes. Estudo clínico e histopatológico. 1986. [Mestrado]. Universidade Federal do Rio de Janeiro, Faculdade de Odontologia, Rio de Janeiro, 1986. 